Canadian University Music Review

Canadian University Music Review

Revue de musique des universités canadiennes

\title{
Schubert's Impromptu in G-flat: A Response to Adam Krims
}

\section{William Renwick}

Volume 20, numéro 2, 2000

URI : https://id.erudit.org/iderudit/1014456ar

DOI : https://doi.org/10.7202/1014456ar

Aller au sommaire du numéro

\section{Éditeur(s)}

Canadian University Music Society / Société de musique des universités canadiennes

\section{ISSN}

0710-0353 (imprimé)

2291-2436 (numérique)

Découvrir la revue

\section{Citer cet article}

Renwick, W. (2000). Schubert's Impromptu in G-flat: A Response to Adam Krims. Canadian University Music Review / Revue de musique des universités canadiennes, 20(2), 31-41. https://doi.org/10.7202/1014456ar
Résumé de l'article

Schubert's Impromptu in G-flat Major is a test case for the varied functions of the upper neighbour. After reviewing Schenker's notion of the upper neighbour, I propose that context is the key to a consistent reading of the upper neighbours in Schubert's Impromptu. The parallelism of neighbours at different levels accounts for much of the organic unity of the composition. Then I reconsider Schoenberg's notion of structural functions, demonstrating the complementary relationship of Schenker and Schoenberg. Finally I revisit the concept of productivity. I argue that most critical approaches employ productivity as a matter of course. The question arises as to which combinations of insight are the most productive.
All Rights Reserved @ Canadian University Music Society / Société de musique des universités canadiennes, 2000
Ce document est protégé par la loi sur le droit d'auteur. L’utilisation des services d'Érudit (y compris la reproduction) est assujettie à sa politique d'utilisation que vous pouvez consulter en ligne.

https://apropos.erudit.org/fr/usagers/politique-dutilisation/ 


\title{
SCHUBERT'S IMPROMPTU IN G-FLAT: A RESPONSE TO ADAM KRIMS
}

\author{
William Renwick
}

Adam Krims touches upon many issues in his discussion of Schubert, Schenker, Schoenberg, and productivity. I would like to put forth different views on some of them. After reviewing Schenker's notion of the upper neighbour, I will revisit Schubert's Impromptu. Then I will reconsider Schoenberg, and finally productivity. Although my interpretations are different, in many ways the conclusions are similar, namely that the combination of viewpoints can yield more insightful analyses. Indeed, I would suggest that this is precisely what the theoretical community is largely engaged in at present.

For a Schenkerian view of musical structure, the significance of the upper neighbour can hardly be overestimated. In many musical contexts it is the neighbour that generates new content, both melodic and harmonic. There is no question that Schenker privileges the role of the upper neighbour: "only the upper neighbour is possible at the first level." The upper neighbour is a form of prolongation of the Kopfton. "The neighbouring note, however humble it may appear to be in content and nature, carries within itself a fundamental musical idea, a great voice-leading occurrence." 2 Briefly, the significance of the upper neighbour is that within the constraints of a linearly constructed melodic background it has unique abilities to prolong the Kopfton. However, the potential of the upper neighbour to create prolongations at the first level of the middleground by no means implies that every neighbour note elaboration of the Kopfton is de facto part of a first-level prolongation.

The manifold forms that Schenker's analytic notation exhibits often serve to distinguish varying roles and emphases among formative structures. This is true for analytical notations of the upper neighbour as well. The analytic symbols that Schenker employs, mostly drawn from musical notation, in many cases represent easily articulated concepts or relationships. In other cases, concepts that the symbols represent are perhaps not so easily or clearly defined or correlated with Schenker's texts. Several notations convey the notion of a structurally significant upper neighbour to the Urlinie, but each carries its unique nuances. As Krims points out, Schenker's use of a half note in Free Composition suggests that the upper neighbour participates to a considerable extent in the form-building role of the Urlinie. This is emphasized when the half note is attached to an overarching beam that spans the Urlinie. The use of a flag on the half note

\footnotetext{
${ }^{1}$ Heinrich Schenker, Free Composition, trans. Ernst Oster (New York: Longman, 1979), 42.

${ }^{2}$ Ibid., 43
} 
might indicate a certain added tension towards resolution of that note. The use of a quarter note rather than a half note suggests that the function of the upper neighbour is less part of the overall form and more part of a melodic or motivic gesture.

Figure $7 \mathrm{~b}$ in Free Composition is a good example of the upper neighbour notated as a beamed half note. In this case it appears as if the upper neighbour is privileged due to its phrase placement as a substitute for what would have been the $\hat{2}$ of an interrupted form. It marks a halfway point in the form of the piece. Similar cases where the upper neighbour forms the basis of a formal design are figures 40-1, 42-1, 49-2, and 153-1 of Free Composition.

In contrast, the upper neighbour in figure 12 , bar 43 , serves to execute a retransition from the end of one section to the beginning of another. Because this upper neighbour carries a subordinate and transitional function, Schenker marks it as an eighth note. The filled notehead indicates its subordinate status; the flag indicates its role as dependent upon a following resolution for its meaning. This type of movement is further explored in Free Composition, figure 23. The subsidiary role of an upper neighbour is clearly shown in Free Composition, figure 76, under the heading "the neighbour note at the later levels." Here Schenker distinguishes the lower ranking of the neighbour by indicating it in black notes, even though the neighbour is functioning directly in relation to the Kopfton or Urlinie.

Figure 32 of Free Composition is illustrative of the varied roles that an upper neighbour may assume. In this example Schenker makes clear that in some instances, such as figure 32-7, the upper neighbour has a retransitional function, as indicated by the flag. (Figure 40-6 of Free Composition is similar.) In some instances the primary role of the upper neighbour is motivic. In Free Composition, figure $130-4 \mathrm{~b}$, the motivic emphasis is on the upper neighbour but the form continues to be developed through prolonging the Kopfton. Here the upper neighbour appears simply as quarter notes.

Despite the distinctions illustrated above, Schenker's notation does not always carry specific one-to-one correspondences of signification. Musical relationships are usually too complex for that. For example, in Free Composition, figure 85 , even though the upper neighbour in bar 26 is a white note attached to the beam of the Urlinie, it is neither prolonged nor indeed consonant. Yet here it seems that it is precisely this neighbour that provides the necessary formbuilding content, the B section of the classic A-A'-B-A' form. Even though this neighbour is contrapuntally weak, it nevertheless represents the essence of the B section as being in a relationship of tension with the surrounding material. Similar but still more complex examples are found in Free Composition, figures 99-2 and 102-2. Figure 153-3b of Free Composition is also instructive. Neighbours appear as black noteheads to indicate motivic content; they are beamed to middleground progressions to indicate form-building at that level (but, as Schenker indicates, they are not tonicized as Krims suggests ${ }^{3}$ ); as well, one of the half-note neighbours is joined to the beam of the Urlinie to indicate

\footnotetext{
${ }^{3}$ Ibid., 143.
} 
that this is the one that builds the essential tension of the piece; the other sets up the return in bar 63. The presence of so many IV harmonies in the opening section prevents the "first-order" neighbour in the middle section from being given similar subdominant support; instead, what is needed is a change of harmony and a building of tension, which is precisely what the dominant seventh does here. It is not that first-order neighbours are not all created equal. Rather, they are not all first-order neighbours!

Is voice-leading ontologically prior to form, as Krims suggests? I think not: form arises out of demands for balance, variety, and continuity. These needs are often met through voice-leading means, of which one of the most important that Schenker "discovers" and describes is the creation of tonal tension and formal contrast through the upper neighbour. Schenker explicitly states all this in his discussion of form, and his examples show how the voice-leading is an agent in the creation of formal contrast. It seems arbitrary to me to separate Schenker's prose from his graphs as Krims does. No doubt the prose and graphs are different media, yet they are both parts of a single discourse, and have to be interpreted as a totality. In an informed reading they complement one another.

In summary, Schenker places great importance on the upper neighbour, but shows that such an upper neighbour can take on a variety of roles, depending upon its context. Understanding the context is therefore the key to a consistent reading of the upper neighbours in Schubert's Impromptu.

Schubert's Impromptu in G-flat Major, D. 899 is in fact a test case for the varied functions of the upper neighbour. To understand the role of the upper neighbour $\mathrm{Cb}$ in the movement as a whole, we first have to understand how the $\hat{3}$ of the opening $\mathrm{G} b$ section $(\mathrm{A})$ is redrawn as $\hat{5}$ of the central $\mathrm{Eb}$ minor section (B). This is the unifying link between the two sections (example 1). In this tonal relationship, $C_{b}$ has no role whatsoever. That is, $B b-C b-B b$ has no place in defining the basic A-B-A' form. Rather, it is the neighbour relationship $D_{b}-E_{b}-D_{b}$ of the inner voice that provides the essential tonal contrast. (That the shift from $\mathrm{D} b$ to $\mathrm{Eb}$ distinguishes the two key areas is Schenker's way of explaining tonal relationships through voice-leading. It is effectively shown in Free Composition, figure 153-2.) Within this background context, $\mathrm{C}_{b}$ functions merely as the upper voice in the contrapuntal $\mathrm{V}$ that returns the music back to $\mathrm{Gb}$ for the $\mathrm{A}^{\prime}$ section of the piece (bar 54). The role of this $\mathrm{C}_{b}$ is neither goal nor self-prolongation but rather a means towards the return to $\mathrm{B} b$ as $\hat{3}$ of the final section. It is thus distinguished in example 1 by carrying an eighth-note flag.

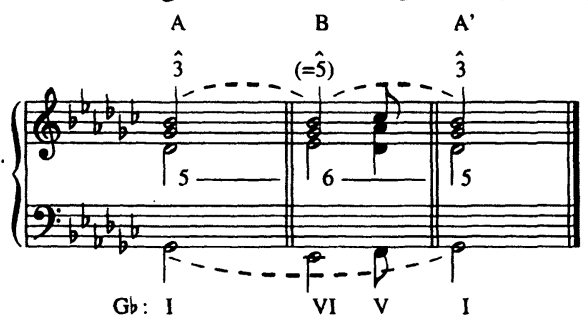

Example 1: Background harmony 
While $\mathrm{Cb}$ therefore has no prolonging role for the Urlinie at the background level, and hence is never elevated above the symbolic weight of an eighth note, it plays a primary role within the $\mathrm{B}$ section itself. Here at this secondary level of structure, $C b$ as upper neighbour functions as the main form-builder in a $\hat{5}-\hat{6}-\hat{5}$ motion (example 2). Read narratively, the $\mathrm{Eb}$ minor section is dramatized by its motion to a prolonged goal of $\mathrm{Cb}$ and subsequent return. It is the contrapuntal VII chord at bar 40 that effects the return to $\mathrm{Eb}$ minor.

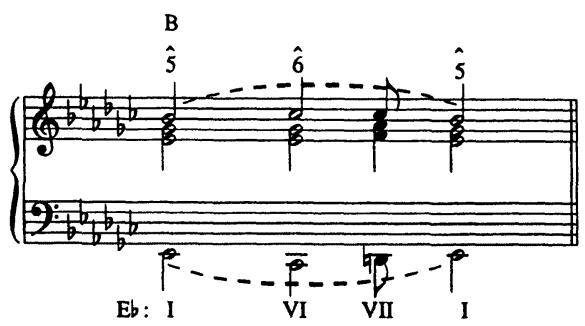

Example 2: B section, background harmony

It is important to note that the $\hat{5}-\hat{6}-\hat{5}$ motion in the inner voice which conjoins the $A, B$, and $A^{\prime}$ sections is reflected in the $\hat{5}-\hat{\sigma}-\hat{5}$ motion of the upper voice which structures the $\mathrm{B}$ section itself. This, an example of parallelism at different levels of structure, goes a long way to asserting the organic unity of the composition in a Schenkerian reading, and at the same time in validating Schenker's conception of structural levels.

Example 3 summarizes the formal aspects of the piece discussed above, including the basic content of the $\mathrm{A}, \mathrm{B}$, and $\mathrm{A}^{\prime}$ sections. In my reading, the first $\mathrm{Cb}$ in the B section appears only as a quarter note, as it is completely subsumed within the prolongation of $\mathrm{B} b$ in the $\mathrm{B}$ section. It is in all ways of subordinate structural importance, notwithstanding its role as goal of a narrative interpretation, by which I mean that $\mathrm{Cb}$ represents the point of furthest harmonic remove from the home stability of $\mathrm{G} b$ major: it is the end of a journey, from which the return to home ( $\left.\mathrm{A}^{\prime}\right)$ begins. On the other hand, the second $\mathrm{Cb}$ in example 3, upper voice, in fact does play a role, however small, in the overall upper-voice structure, in that it effects the return to $\mathrm{A}^{\prime}$. Paradoxically, the $\mathrm{Cb}_{b}$ which marks the dramatic apex of the piece, in the middle of the B section, is of less structural weight than the second $\mathrm{C}_{b}$ which is transitory, in the move from $\mathrm{Eb}$ minor back to $G$ b major.

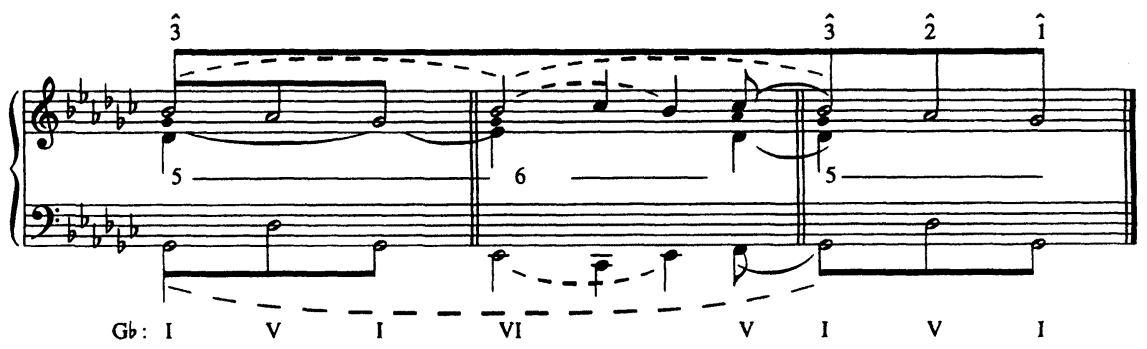

Example 3: Middleground 
Comparison of example 3 with Krims's Graph Z illustrates this difference. The bass line of Krims's graph can only be read as a motion from $\mathrm{G} b$ through $\mathrm{Eb}$ to $\mathrm{Cb}_{b}$ and back again, since the stems of the Ebs are neither attached to the beam nor connected to one another to form a prolongation. But in my reading of the B section the two Ebs are a single prolongation which constitutes the B section of the piece, elaborated by $\mathrm{Cb}$ as "consonant support" or harmonization of the upper neighbour $\mathrm{Cb}$. What Krims's bass line shows us is in fact not the tonal structure but the path of the narrative.

A small but important point about Krims's Graph $Y$ is that the upper voice $\mathrm{B} b$ at bar 55 is curiously downplayed. It appears as a quarter note, even though at Level $\mathrm{Z}$ it is marked as a half note attached to the beam of the Urlinie. In Graph X, too, this note is downplayed: it is not even attached to the least of the three beams that appear at this point. But this very $\mathrm{B} b$ marks the beginning of the A' section, the point at which the Urlinie resumes its initial function and the point from which the concluding descent begins. It appears to me that Krims would downplay the role of the $\mathrm{C}_{\mathrm{b}}$ in bar 54 by subsuming it in a third progression of the upper voice spanning bars $42-62$. What is lost in this reading is the distinction between the $\mathrm{B} b$ as principal upper voice of the $\mathrm{B}$ section, and the subsequent return to $\mathrm{B} b$ as beginning of the final $A$ section.

For the sake of comparison, I include at this point several additional graphs that complete my reading of the piece. Example 4a provides detail on the structure of the A section. This view shows the A section to be essentially a binary form, in which the first part, bars 1-8, appears as an interruption-an antecedent-consequent pattern. The concluding part of the binary form is intensified through prolongation of the $\hat{2} / \mathrm{V}$ in bar 9 . One might argue that the conventionality of the A section calls for a more radical treatment in the $\mathrm{A}^{\prime}$ section later on. Example $4 \mathrm{~b}$ is mostly useful in showing how the $\mathrm{C}_{b}$ idea which is the issue of the $\mathrm{B}$ section is incorporated within the A section, through the initial bass arpeggio (bars 1-3), and as the apex of the sequential passage in bars 9-12.4

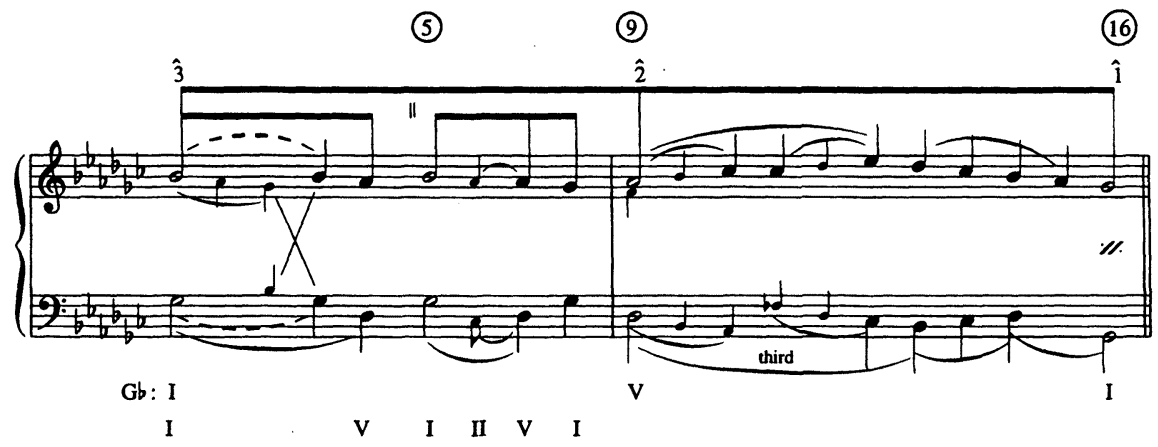

Example 4a: A section; middleground

${ }^{4}$ Schenker provides a graph of this sequence in Free Composition, Figure 110 b)-2. 
(5)

(9)

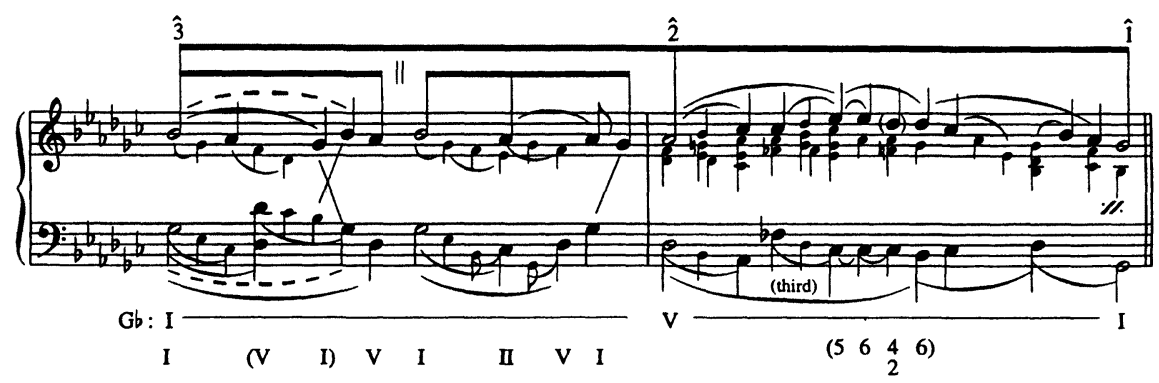

Example 4b: A section; foreground

Example 5 illustrates my view of how the $\hat{5}-\hat{6}-\hat{5}$ motion is worked out in the B section. My graph suggests that the move from $B b$ to $C b$ occurs as early as bar 32, in the inner voice, whereas Krims shows the $\mathrm{B} b$ prolonged until bar 35 . Here I am really making a distinction between strict voice-leading, by which the $\mathrm{Cb}$ displaces $\mathrm{Bb}$ in bar 32 as the music moves into the key of $\mathrm{Cb}$ on the one hand, and melodic shaping, where the $\mathrm{Cb}$ asserts itself as a melodic factor only beginning at bar 35 on the other. But for me bars 35-39 mark the place where $\mathrm{Cb}_{\text {is }}$ reached as a goal, and dwelt upon in a temporary relaxation of tension. This is represented by the beamed passage in the middle of example 5, which is based on a transference of the fundamental structure to the foreground. That is, there is a tiny 3-2-1 melodic motion resolving in a perfect authentic cadence that marks this point of resolution in a foreign key. (A small point of difference here also is that I would read the $\mathrm{Db}$ of bar 31 as resolving down to $\mathrm{Cb}$, not up to $\mathrm{Eb}$.)
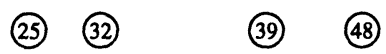

(55)

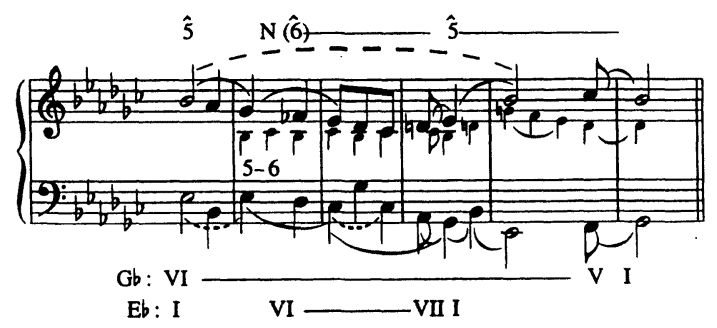

Example 5: B section, neighbour motion

Example 6 provides detail on the structure of the B section. In particular it shows how the $\mathrm{Cb}_{b}$ is prolonged through the course of the $\mathrm{Cb}$ major section, bars $32-39$, and that $\mathrm{B} b$ remains the principal melodic note of the $\mathrm{B}$ section. It is worthwhile to point out that the move to $\mathrm{Eb}$ major near the end of the B section is a chromaticism which arises out of formal considerations. Bars 49-51 repeat the transference of the fundamental structure that occurred in bars 33-35 as a 
way of closing the B section on a perfect authentic cadence in $\mathrm{Eb}$. It is this closure at bar 51 that defines the succeeding three measures as a retransition set apart from the $\mathrm{B}$ section proper-and this is how the $\mathrm{Cb}$ in bar 54 gains its structural status.

(25)

(31)

(39)

(48)

(55)

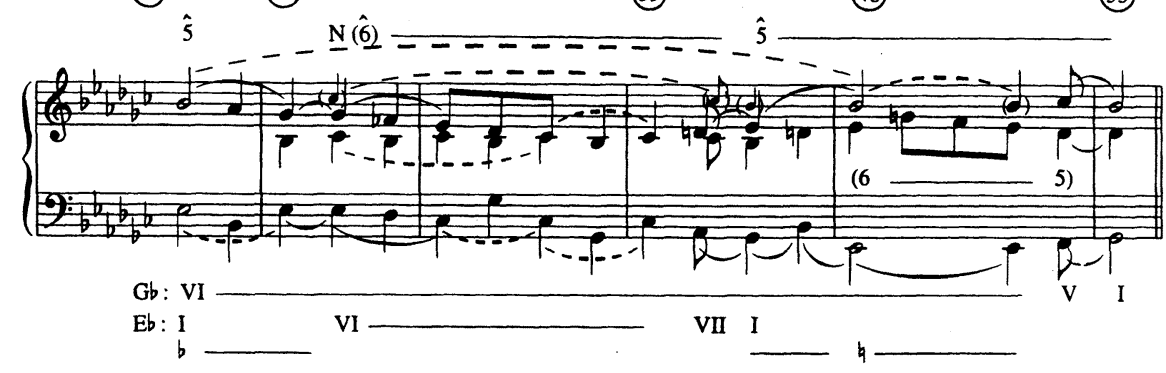

Example 6a: B section; middleground

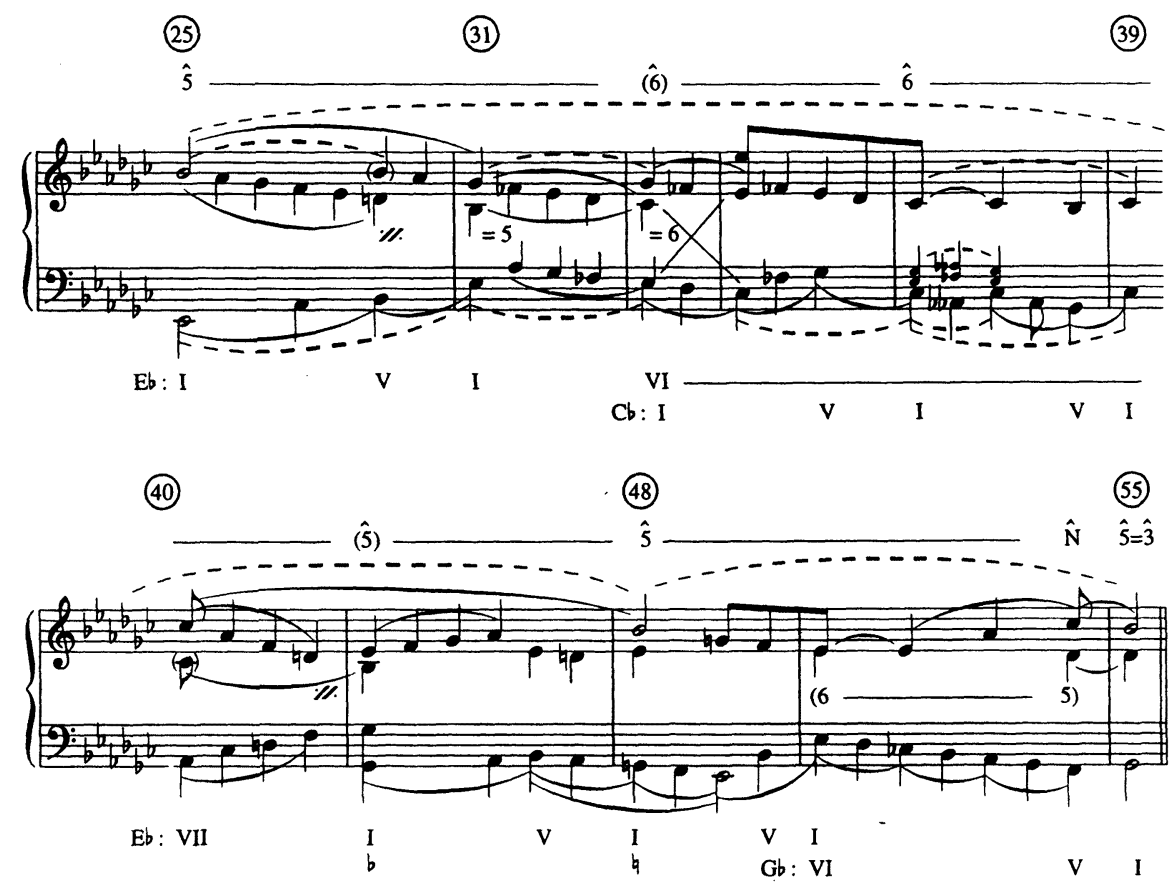

Example 6b: B section; foreground

Finally I will point out how the music of the $A^{\prime}$ section forms a varied reprise and conclusion. While bars 55-62 correspond with bars 1-8, bars 63-73 constitute an expanded version of bars 9-16. After that, bars $73 \mathrm{ff}$. constitute a coda. 
The expansion at bars 63-67 integrates materials and heightens the tension by reemphasizing the $C b$ harmony (bars 66-67 and 69-70) and by delaying the perfect authentic cadence. The coda is built primarily on the idea of the descending stepwise bass $\mathrm{G} b-\mathrm{C}$, an expanded form of the opening bass progression $\mathrm{G} b-\mathrm{E} b-\mathrm{C} b$ in bars $1-3$. But the bass undergoes further chromaticism, first through $\mathrm{C}_{b}$ minor, and subsequently through Abb minor (notated enharmonically as $\mathrm{G}$ minor), a minor form of the Neapolitan (bII). This idea reflects the minor IV harmony that prolongs the $\mathrm{Cb}$ arrival at bar 45 , and likewise reflects the descending bass of the retransition at bars 51-53. Added to this, the motion to the cadential six-four arises through the augmented sixth.

Figure 100-3f of Free Composition shows Schenker's view of the coda, highlighting the use of an upper neighbour $A b b$ ( $G$ natural) which reflects prior upper neighbours, as well as the bass descent that outlines the familiar pattern $G b$, $\mathrm{E} b \mathrm{~b}, \mathrm{C} b \mathrm{~b}$, a chromaticized version of the original $\mathrm{G} b-\mathrm{E} b-\mathrm{Cb}$ of bars $1-2$. This graph also shows how a voice exchange leads from this harmony to the augmented sixth that follows. (Like the one mentioned above, this is a graph of the actual piece: it certainly deserves a mention in a discussion of Schenker's view of the Impromptu. Interestingly, both of these graphs appear in G major, the key of the first edition.)

In sum, while both the pitch and the harmony $\mathrm{Cb}$ have much to do with the content of Schubert's Impromptu, they in fact have little to do with the deeper levels of structure.

With regard to Schoenberg, there is no question, I think, that he sees keys and regions as form-building elements that provide contrast, but that are also related to one another. The essence of his scheme is a two-dimensional grid, the vertical axis of which expresses fifth relationships, and the horizontal axis of which expresses third relationships and mixture. ${ }^{5}$ In this view, $\mathrm{E} b$ minor still works as the contrasting subordinate key one step removed from $\mathrm{Gb}$ major, and $\mathrm{Cb}$ major, a diagonal move away from $\mathrm{Eb}$ minor (a fifth relation to the original $\mathrm{Gb}$ ) still works as the "point of furthest harmonic remove" that constitutes the central goal of the B section. But while the Schenkerian or linear view shows the relationship among these keys through the employment of $\hat{5}-\hat{6}-\hat{5}$ motions, first on $\mathrm{D} b$ and then on $\mathrm{B} b$, Schoenberg characterizes such moves as harmonic or root motions by third and by fifth.

In "Schenker and Schoenberg: A Critical Comparison," Barbara Hampson explores the viewpoints of the two theorists in detail. ${ }^{6}$ Drawing on Schoenbergian concepts of tonality as explicated by Patricia Carpenter, Hampson suggests that in many cases Schenker and Schoenberg were looking at the same ideas, but, as it were, through opposite ends of a telescope. ${ }^{7}$ Typically, where Schenker might see motivic gestures as reflecting the essential background, Schoenberg would see motivic gestures as germs from which the larger ideas, especially those of

\footnotetext{
${ }^{5}$ Arnold Schoenberg, Structural Functions of Harmony (New York: Norton, 1969), 20.

${ }^{6}$ Barbara Hampson, "Schenker and Schoenberg:A Critical Comparison" (M.A. thesis, McMaster University, 1993).

${ }^{7}$ Patricia Carpenter, “Grundgestalt as Tonal Function,” Music Theory Spectrum 5 (1983): 15-38.
} 
key relationship, would emerge. In the Schubert Impromptu, for example, a Schoenbergian view might suggest that the initial melody notes $\mathrm{B} b$ and $\mathrm{Gb}$ form a third which implies an initial tonality of $\mathrm{G} b$. This third is completed as a tonic chord by the addition of $\mathrm{Db}$, but at the same time opens the way to $\mathrm{Eb}$ minor by incorporating $\mathrm{E}_{b}$ instead of $\mathrm{D} b$, thus yielding the basic tonality of the $\mathrm{B}$ section. Similarly, Schenker might see the dramatic action of the movement to $\mathrm{Cb}_{b}$ major in the B section as foreshadowed in the bass of bars 1-3, whereas Schoenberg might see the initial bass progression as opening the way for a later expansion where the chord of IV in bar 3 leads to the key of IV later on.

Krims notes that "in most contemporary music-theoretical works the music is treated as an object whose properties are to be discovered by a theoretical system." It is quite possibly true that most theorists often treat music as an object whose properties are to be discovered, but I think that most theorists would be happy to use whatever will help to reveal the properties of a piece of music. Further, I disagree that a piece is "praised for the masterful way in which it reflects the theory." We would no doubt make exceptions for the case where a theorist is engaged in creating a theory. This enterprise typically does need to be substantiated by examples from the literature. Much of this approach reflects the traditions of the scientific method of inquiry. Yet for established theory, justification of the theory itself is usually not the issue when the focus or discourse is the structure or content of a given work or works. However, I do agree with Krims that "the process of analysing a work may reconfigure, in some basic way, the methodologies that one brings to it." After all, this is the story of Schenker's own analytical development.

In terms of productivity, it seems to me that the nexuses of productivity in Krims's paper are not Schenker and Schubert, but Krims and Schubert-this because it is Krims's analytical graph that is the basis of the discussion. Krims may claim that his graphs represent a Schenkerian view, but comparison with mine will illustrate the degree to which Schenkerian analysis is interpretive. A comparison with Hampson's work mentioned above may clarify: in Hampson, we see the closest possible parallel alignment and comparison of Schenkerian and Schoenbergian approaches to a single composition. This close scrutiny reveals how two powerful minds view similar structural relationships often from different angles. Yet they are by and large complementary views arrived at by opposing means, not opposing views. But Krims's model of productivity with reference to Schenker is one step removed, for it is Krims's analysis, not Schenker's, that is the basis of the criticism. In this context, my analysis provides a foil.

One can hardly disagree that the combination of approaches that productivity suggests is a positive methodology. I would argue that most critical approaches employ productivity in this sense. However, the question will always arise as to which combinations of insight will be the more productive-the more significant—and which will be relatively uninformative. Just as in the economy, some kinds of productivity are more productive than others. The analyst makes choices at some point, as to which theoretical tools hold promise for informing a given work or grouping of works. 
I note in passing that Schenker in fact follows two of the pillars of Kristeva's theory of structural linguistics: namely "immediate constituent analysis" and "generative grammar"; the former in that Schenkerian method is all about dividing musical utterances into ever smaller units of structure in a hierarchical system, the latter in that his generative philosophy of tonality emerges from tone and Klang and prolongs itself in multitudinous ways as presented in Free Composition. ${ }^{8}$ After all, these foundations of linguistic theory parallel the background to foreground and foreground to background directions of analytical thought that Schenker pioneered in the 1920s.

Most Schenkerians would agree with Krims that Schenkerian analysis does not say all that there is to be said about a given piece of music. They would also agree that Schenkerian analysis is subjective to the extent that it is interpretive. Yet much of the time it relates to concepts of musical grammar; concepts concerning harmony, cadence, closure, etc., which have been discerned for centuries. Krims has attempted to "deconstruct" Schenker, or prove him to be inconsistent. I am not sure that anyone would claim Schenker or anyone else to be perfectly consistent. However, a more careful reading of Schenker is more likely to shed light on the subtleties of Schenker's thought rather than on its inconsistencies. It is for this reason that I object to Krims's claim to have shown Schenker analysis to be a "fundamentally heterogenous object." Rather, for most analysts it is the synthetic potential of Schenker's approach-its ability to respond to and reflect the subtleties of detail-that is among its most compelling aspects. The foregoing discussion of Schenker's theory and its application is intended to show these features in a better light.

I would argue that Schenker's interaction with music over an extensive period is an example of productivity in its own right. By spending so much effort studying music and attempting to articulate its tonal structure, Schenker developed and reshaped his view of music again and again. As early as Der Tonwille (1921-24), he seems to have felt a certain plateau of understanding and articulation of his thoughts, and it is during this time that we see the publication of the Erläuterungen, or "Elucidations," his first real attempt to create a theory that embodied his views. Even his notion of Urlinie changed substantially over time. Likewise his use of analytic notation continued to evolve. In terms of production theory, the continual interaction between the music that Schenker analysed and Schenker's responses to it produced the analytical technique, if you will.

It may be true, although I do not believe it, that Schenkerians have been hesitant to contextualize Schenkerian theory. One needs to look at Schenker reception to understand this view. First, only with the English translation of Free Composition in 1979, just twenty-one years ago, did most theorists have an opportunity to come to grips with Schenker's theories. Even today not all of his published writing is available in English translation. During the 1980s, much of the energy of the theoretical community was devoted to absorbing and understanding what Schenker was saying, and to retooling undergraduate and graduate theory curricula to reflect those insights. This integration of Schenkerian ideas and ideals into university curricula, yielding a revised, and hopefully more

${ }^{8}$ Julia Kristeva, Language:The Unknown (New York: Columbia University Press, 1989), 243, 253ff. 
insightful approach, is another example of productivity. This process has been followed by a period of more critical evaluation, leading to a period of "reconciliation" if you will, of Schenkerian with other methods of analysis. A good example of this would be Kofi Agawu's Playing with Signs: A Semiotic Interpretation of Classic Music, ${ }^{9}$ which interweaves Schenkerian principles with rhetorical considerations. Another is Robert Snarrenberg's Schenker's Interpretive Practice,$^{10}$ which contextualizes Schenker brilliantly.

There can be no question that music informs analysis and that various analytical techniques, especially those that appear at first to arise from quite different concerns, can inform each other. Has it ever been different? We should, however, be wary that productivity-like Schenkerian analysis-does not lead to sterility. One could take the view that Schenker's theory should be made perfectly consistent and that all voice-leading features should be indicated a certain way only. A standardized theory such as that would conform to a rulebased system. At its worst, such an approach becomes a reductive procedure that any well-programmed computer could perform, the results of which are entirely predictable and entirely uninteresting. At its best it provides insights into what is systematic about tonal music and what is not, as in the work of Fred Lerdahl and Ray Jackendoff. ${ }^{11}$ Attempts to systematize Schenkerian notationtypically in the interests of pedagogy-in fact impoverish the theory by demanding a conformity that robs us of unique and creative expression of musical relationships. ${ }^{12}$ I do not doubt that if Schenker himself had been presented with a complete and completely systematic analytical method, he would have lost interest in analysing music. Thankfully, music is resistant to comprehensive analysis; it provides continual challenges and rewards.

\section{Abstract}

Schubert's Impromptu in G-flat Major is a test case for the varied functions of the upper neighbour. After reviewing Schenker's notion of the upper neighbour, I propose that context is the key to a consistent reading of the upper neighbours in Schubert's Impromptu. The parallelism of neighbours at different levels accounts for much of the organic unity of the composition. Then I reconsider Schoenberg's notion of structural functions, demonstrating the complementary relationship of Schenker and Schoenberg. Finally I revisit the concept of productivity. I argue that most critical approaches employ productivity as a matter of course. The question arises as to which combinations of insight are the most productive.

\footnotetext{
${ }^{9}$ Kofi Agawu, Playing with Signs: A Semiotic Interpretation of Classic Music (Princeton, N.J.: Princeton University Press, 1991).

${ }^{10}$ Robert Snarrenberg, Schenker's Interpretive Practice (Cambridge: Cambridge University Press, 1997).

${ }^{11}$ Fred Lerdahl and Ray Jackendoff, A Generative Theory of Tonal Music (Cambridge, Mass.: MIT Press, 1983).

${ }^{12}$ Felix Salzer, Structural Hearing: Tonal Coherence in Music, 2 vols. (New York: Dover Publications, 1962); Allen Forte and Steven Gilbert, An Introduction to Schenkerian Analysis (New York: W.W. Norton, 1982). Schenker's analytic notation itself evolved throughout his career, and must be read in context. See for example William Renwick, "Brackets and Beams in Schenker's Graphic Notation," Theoria 3 (1988): 73-85.
} 